\title{
Survival of bovine embryos transferred to progesterone-treated asynchronous recipients
}

\author{
R. D. Geisert ${ }^{1}$, T. C. Fox ${ }^{1}$, G. L. Morgan ${ }^{2}$, M. E. Wells ${ }^{3}$, R. P. Wettemann ${ }^{1}$ \\ and M. T. Zavy ${ }^{4}$
}

'Oklahoma Agricultural Experiment Station and ${ }^{2}$ Department of Veterinary Medicine and Surgery, Oklahoma State University, Stillwater, OK 74078, USA; ${ }^{3}$ Reproductive Enterprises, Stillwater, OK 74074, USA; ${ }^{4}$ U.S. Department of Agriculture, ARS, El Reno, OK 73036, USA

\begin{abstract}
Summary. Treatment of recipient cows with $100 \mathrm{mg}$ of progesterone daily from Days 1 to 5 of the oestrous cycle increased plasma progesterone compared with vehicle-treated recipients. Embryo transfer to progesterone-treated recipients which showed oestrus $72 \mathrm{~h}$ after the donor cows resulted in pregnancy rates at Day 35 similar to those of synchronous $( \pm 12 \mathrm{~h})$ recipients $(42$ vs. $50 \%)$. Only 1 of $22(4.8 \%)$ asynchronous $(-72 \mathrm{~h})$ vehicle-treated recipients established pregnancy. Similar treatments of cyclic cows with progesterone shortened $(P<0.01)$ the interoestrous interval by 3.2 days. When assessed on Day 7 of pregnancy, administration of progesterone to superovulated donor cows on Days $1-4$ of pregnancy did not affect early embryo development compared with superovulated cows treated with vehicle alone. Plasma progesterone increased rapidly in superovulated cows compared with cows during the oestrous cycle. The results indicate that administration of progesterone early in the oestrous cycle of the recipient can effectively advance uterine receptivity for the transfer of older asynchronous embryos.
\end{abstract}

Kelwords: bovine; embryo; uterus; progesterone

\section{Introduction}

The establishment and maintenance of pregnancy in domestic farm species involves intricate intercommunication between the developing conceptus and the maternal endometrium. Embryo transfer studies in sheep (Moore \& Shelton, 1964; Rowson \& Moor, 1966) and cattle (Rowson et al., 1972; Betteridge et al., 1980) have clearly demonstrated a need for close synchrony ( $\pm 24 \mathrm{~h})$ between embryo and the uterine environment of the recipient. Although attention to synchrony between donor and embryo and assessing the quality of embryos transferred has improved the success of embryo transfer, a large percentage of embryos classified as excellent or good do not survive (see review Markette et al., 1985). Early embryo loss could result from chromosome defects. Wilmut et al. (1986) reported that chromosome abnormality occurred in $7.5 \%$ of bovine embryos tested. However, $<2 \%$ chromosome defects were reported in blastocysts collected from superovulated cows (Hare et al., 1980), which suggests that, if embryo quality is good, the most likely cause of embryonic loss is an inappropriate uterine environment.

Wilmut et al. (1986) indicated that early embryonic loss could occur through an inadequate uterine environment resulting from an inherently abnormal reproductive tract or variation in the normal pattern of endocrine secretions. Endometrial secretion, essential for stimulating and mediating changes in conceptus growth and differentiation throughout early pregnancy, is directed by the steroid environment generated by the ovary. Progesterone synthesis and secretion by the corpus luteum play a major role in regulating the secretory patterns of the maternal endometrium. 
Studies in ewes (Wilmut \& Sales, 1981; Lawson et al., 1983) and cows (Garrett et al., 1988b) have suggested that maternal progesterone regulates early conceptus growth and development. Bovine conceptus development is regulated, at least in part, by endometrial secretions, which are influenced by the time and quantity of progesterone secreted or administered (Wilmut \& Sales, 1981; Garrett et al., 1988b). Ashworth et al. (1989) provided evidence of a close association between periovulatory plasma progesterone and embryo survival in ewes. Limited data (Maurer \& Echternkamp, 1982; Lamming et al., 1989) also suggested that the concentration of progesterone in serum and milk is positively correlated with embryo survival in cattle.

In theory, if progesterone was given to recipient females, the timing of uterine development as well as synchrony between embryo and uterus could be more precisely regulated. Studies in sheep have demonstrated that progesterone administration during the first few days of the oestrous cycle allows recipient ewes to establish pregnancies with older ( +4 days) embryos (Lawson \& Cahill, 1983). The effects of progesterone administration on transfer of asynchronous bovine embryos are unknown. The present study determined (i) whether progesterone administration allows recipient cows (Day 5) to establish and maintain pregnancy with older ( +3 days) embryos and (ii) to the effect of progesterone administration on early embryo development in superovulated cows.

\title{
Materials and Methods
}

\begin{abstract}
Animals. Fifty-four nonlactating, multiparous (8-12 years), cyclic beef cows, maintained in dirt lots and fed protein supplement and prairie hay to maintain good body condition, were observed twice a day (morning and afternoon) for oestrous behaviour (oestrus $=$ Day 0 ). Upon detection of oestrus in Exp. 1, superovulated donor cows were mated to bulls of known fertility. Superovulated cows used for collection of embryos in Exp. 2 were artificially inseminated 12 and $24 \mathrm{~h}$ after onset of standing oestrus. Frozen semen used for insemination in Exp. 2 was obtained from a single cjaculate of a sire of known fertility.
\end{abstract}

Superovulation, embryo collection and transfer. Oestrus was synchronized by two $25 \mathrm{mg}$ intramuscular (i.m.) injections of Lutalyse (Upjohn Veterinary Products, Inc., Kalamazoo, MI, USA) given 11 days apart. Cows were injected i.m. with a total of $40 \mathrm{mg}$ of follicle-stimulating hormone FSH-P (Schering Co., Kenilworth, NJ, USA) over 4 days, initiated on Days 913 after oestrus (oestrus $=$ Day 0 ). Donors were treated twice a day with FSH doses of 8,6 , 4 and $2 \mathrm{mg}$. Lutalyse $(30 \mathrm{mg})$ was injected, i.m., 48 and $60 \mathrm{~h}$ after initiation of FSH-P treatment. Embryos were nonsurgically flushed with a Foley catheter on Day 8 (Exp. 1) or Day 7 (Exp. 2). After an epidural injection of lidocaine, uteri were flushed with I litre of Dulbecco's phosphate-buffered saline (PBS; EM Flush II, Em-Tex Supply Co., Inc., Arlington, TX, USA) containing $1 \%$ antibiotic-antimycotic ( $100 \mathrm{U}$ penicillin, $100 \mu \mathrm{g}$ streptomycin and $0.25 \mu \mathrm{g}$ amphoterrin $\mathrm{B} / \mathrm{ml}$ ) and $1 \%$ foetal calf serum (Sigma Chemical Company, St Louis, MO, USA). Embryos recovered from flushing media were transferred into Dulbecco's PBS with $1 \%$ antibiotic-antimycotic and $10 \%$ foetal calf serum. Based on visual appraisal, only excellent and good quality embryos were transferred to recipient females. Embryos were transferred nonsurgically into recipients with a Cassou inseminating gun inserted into the vagina and passed through the cervix to the uterine horn ipsilateral to the ovary containing the corpus luteum within $4-7 \mathrm{~h}$ of embryo recovery.

Experiment 1. A total of 13 multiparous cows were superovulated in 2 replicate experiments. Day- 8 blastocyst or late morula embryos collected from donor cows were pooled and randomly assigned to be transferred to 1 of the following recipient treatment groups: (1) Day-8 embryo transferred to Day-8 recipient (synchronous control); (2) Day-8 embryo transferred to Day-5 recipient (asynchronous control); and (3) Day-8 embryo transferred to Day-5 recipient given i.m. injections (100 mg) of progesterone (Henry Schein, Inc., Port Washington, NY, USA) on Days 1 , 2,3 and 4 of the oestrous cycle (asynchronous progesterone). The first progesterone injection (Day 1) was given $36 \mathrm{~h}$ after the first observation of oestrous behaviour; the remaining injections were administered at 24-h intervals thereafter. Recipient females were treated with Lutalyse $(25 \mathrm{mg}$ ) to initiate oestrus $+24 \mathrm{~h}$ (Group 1 ) or $-72 \mathrm{~h}$ (Group 2 and 3) from onset of oestrus in donor cows.

Blood samples $(10 \mathrm{ml})$ were collected daily from recipients by jugular venepuncture from Days I to 5 . Samples were placed on ice, transported to the laboratory and centrifuged at $2400 \mathrm{~g}$ for $15 \mathrm{~min}$ at $4^{\circ} \mathrm{C}$. Plasma was decanted and stored at $-15^{\circ} \mathrm{C}$ until analysed for progesterone content.

Following transfer of embryos, recipients were observed for oestrous behaviour twice a day. Pregnancy was confirmed by transrectal ultrasonography on Days 25,35 and 45 of gestation. Ultrasonography was conducted with an Aloka 210 Ultrasound (Corometrics Medical Systems, Inc., Wallingford, CT, USA) using a $5-\mathrm{mHz}$ probe.

To confirm that progesterone treatment during Days 1-5 of the oestrous cycle reduces interoestrous interval (Garrett et al., 1988a), an additional group of cyclic cows was injected with maize oil $(n=19)$ or progesterone $(n=25)$ as described previously. Cows were checked for oestrous behaviour daily. 
Experiment 2. To determine whether progesterone administration from Days 1 to 4 of pregnancy alters early embryo development, 18 multiparous beef cows were superovulated with FSH-P as previously described. Cows were artificially inseminated with frozen semen from a single sire of known fertility. Cows were inseminated at 12 and $24 \mathrm{~h}$ after the onset of oestrus and randomly assigned to receive daily i.m. injections of maize oil $(n=8)$ or $100 \mathrm{mg}$ progesterone $(n=10)$ on Days $l-4$ (Day $0=$ onset of oestrus). Injections were started $36 \mathrm{~h}$ after initiation of oestrus. Embryos were recovered nonsurgically on Day 7 and classified as to their developmental stage. Blood samples were collected from Days I to 5 for analysis of plasma progesterone content. In addition, blood samples were collected from Days I to 5 of the oestrous cycle from control $(n=5)$ and progesterone-treated $(n=5)$ nonsuperovulated cows. Progesterone $(100 \mathrm{mg}$ ) was administered daily from Days $\$ to 4 as previously described for superovulated cows.

Peripheral plasma progesterone analysis. Plasma samples were analysed for progesterone concentration by radioimmunoassay as previously described and validated by Lusby et al. (1981). Intra- and interassay coefficients of variation were 8 and $13 \%$, respectively.

Statistical analysis. Data were analysed by least square analysis of variance using the General Linear Models procedures of the Statistical Analysis System (Spector et al., 1985). Split-plot analysis of variance (Steel \& Torrie, 1980) was used for determination of treatment differences in plasma progesterone concentration. The statistical model for analysis of concentration of progesterone in plasma for Exp. I included the effects of treatment (synchronous control, asynchronous control and asynchronous progesterone), cow-within-treatment, day and treatment $\times$ day interactions. Cow-within-treatment was the error term used to test treatment effects. Preplanned comparisons were made for (i) asynchronous control vs. synchronous control and asynchronous progesterone-treatment and (ii) asynchronous progesterone vs. synchronous control. The statistical model for plasma progesterone analysis in Exp. 2 included treatment (superovulated, superovulated + progesterone, cyclic, and cyclic + progesterone), cow-within-treatment, day and treatment $\times$ day interaction. Preplanned comparisons were made for (i) superovulated + progesterone vs. superovulated, cyclic and cyclic + progesterone; (ii) superovulated vs. cyclic and cyclic + progesterone; and (iii) cyclic vs. cyclic + progesterone. Pregnancy rates of embryo recipients in Exp. I were compared by $\chi^{2}$ analysis (Steel \& Torrie. 1980). Effect of progesterone on number of embryos and development in superovulated donors (Exp. 2) was analysed by split-plot analysis of variance after log transformation. Embryo stages were assigned the following numbers for statistical evaluation: unfertilized oocytes (0), degenerative embryos (3), compacted morula (4), early blastocyst (5), blastocyst (6), expanded blastocyst (7) and hatched blastocyst (8). The statistical model for analysis of number of embryos, viable embryos and embryo development included effects of treatment, cow-within-treatment, stage of embryo development and treatment $\times$ stage interactions. Cow-within-treatment was the error term used to test treatment effects.

\section{Results}

\section{Experiment 1}

The effect of replicate was not significant $(P>0 \cdot 10)$; therefore, results were combined for all analyses. Transferable, excellent and good-quality embryos were obtained from 9 of 13 donor cows. A total of 104 embryos ( 72 blastocyst and 32 morula) were collected for nonsurgical transfer to recipient females. Overall pregnancy rate, as determined by transrectal ultrasonography, was not different $(P>0 \cdot 10)$ between synchronous control $(11 / 18,61 \cdot 1 \%)$ and asynchronous progesteronetreated $(9 / 19,47 \cdot 4 \%)$ recipients at Day 25 of gestation. However, pregnancy rate of asynchronous control recipient cows was less $(P<0.01)$ than in the other 2 recipient groups $(1 / 21,4.8 \%)$. Two synchronous control and one asynchronous progesterone-treated recipients aborted embryos after detection at Day 25 of gestation. Although embryos were lost after Day 25 in the 2 groups, statistical significance between treatment groups was unchanged.

Plasma progesterone increased $(P<0.01)$ from Days 1 to 5 of the oestrous cycle for cows in all treatments. Concentration of progesterone in plasma was greater in asynchronous progesteronetreated recipients $(P<0.01)$ than in synchronous- and asynchronous-control recipients (Fig. 1). Plasma progesterone concentration was $>2 \mathrm{ng} / \mathrm{ml}$ on Day $2(24 \mathrm{~h}$ after progesterone treatment $)$ in asynchronous progesterone-treated recipients and increased to $5-6 \mathrm{ng} / \mathrm{ml}$ by Day 5 . In contrast, plasma progesterone concentration did not reach $2 \mathrm{ng} / \mathrm{ml}$ until Days 4 or 5 of the oestrous cycle in the recipient groups not receiving exogenous progesterone. When scaled to initiation of oestrus (Day 0), plasma progesterone concentration was similar in synchronous- and asynchronous-control recipients. 


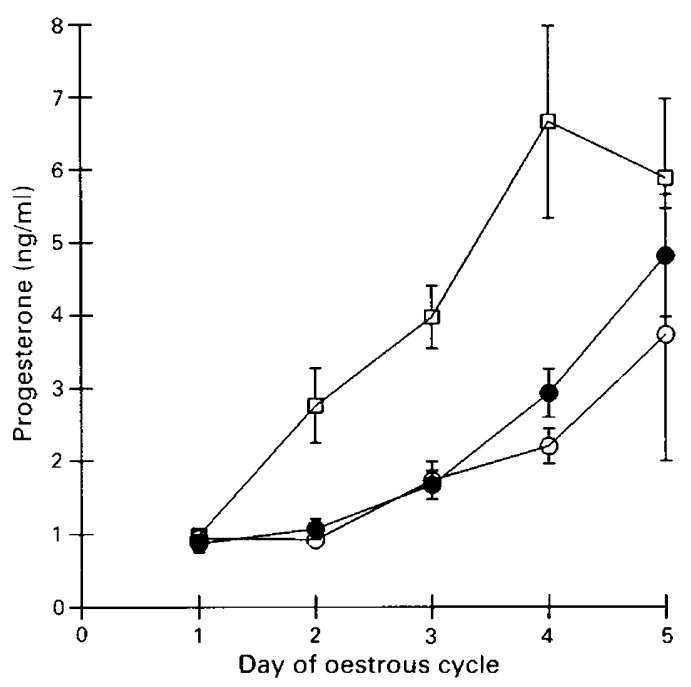

Fig. 1. Peripheral plasma progesterone concentrations in progesterone-treated asynchronous $(\square)$, control asynchronous (Q) and control synchronous (O) recipient cows. Asynchronous control and asynchronous progesterone-treated recipients' plasma progesterone concentrations were scaled to the oestrous cycle of the synchronous control recipients. Day- 8 embryos were transferred to asynchronous control and asynchronous progesterone-treated recipients on Day 5 of their oestrous cycles compared with Day 8 in synchronous control recipients.

Average interoestrous interval was shortened $(P<0.01)$ by 3.2 days in progesterone-treated cyclic cows $(18.3 \pm 0.23$ days $)$ compared with vehicle-treated control cyclic cows $(21 \cdot 5 \pm 0.26$ days).

\section{Experiment 2}

Fertilized embryos were flushed from 7 of 8 vehicle-treated and 8 of 10 progesterone-treated superovulated cows. A total of 108 and 65 ova were recovered from vehicle- and progesteronetreated cows, respectively. The mean number of ova recovered was greater $(P<0.03)$ in vehicle$(13 \cdot 5 \pm 2 \cdot 1)$ than in progesterone-treated $(6 \cdot 5 \pm 1 \cdot 9)$ cows, but the mean number of viable embryos from cows which contained fertilized ova was similar $(P>0 \cdot 10)$ in vehicle- $(9.4 \pm 1.6)$ and progesterone-treated $(6.5 \pm 1.8)$ cows. A wide range of viable embryos recovered was observed in both groups of superovulated cows. The number of viable embryos recovered varied from 1 to 19 in the present study. Based on subjective numerical classification (see Materials and Methods), development of fertilized embryos recovered from superovulated control and progesterone-treated cows was similar $(P>0 \cdot 10)$ (Table 1).

Concentration of progesterone in plasma of superovulated cows was not different $(P>0 \cdot 10)$ between treatment groups (Fig. 2a). Treatment $\times$ day interaction $(P<0.01)$ was detected when plasma concentration of progesterone in cows from Days 1 to 5 of the oestrous cycle or treated with progesterone during the early oestrous cycle was compared with that in superovulated cows. Progesterone administration to cows during Days $1-5$ of the oestrous cycle increased $(P<0.01)$ plasma progesterone concentration compared with vehicle-treated cyclic cows as observed in Exp. 1 (Fig. 2b). Administration of progesterone to nonsuperovulated cows resulted in an increase of plasma progesterone $>2 \mathrm{ng} / \mathrm{ml}$ on Day 2 which was comparable to the increase in superovulated cows, but plasma progesterone concentrations increased rapidly on Days 3-5 in superovulated cows compared with progesterone-treated cyclic cows. Plasma progesterone concentrations of superovulated cows were $20-25 \mathrm{ng} / \mathrm{ml}$ on Day 5 compared with $6 \mathrm{ng} / \mathrm{ml}$ in cows administered progesterone during the oestrous cycle. 
Table 1. Bovine embryo development donors treated with $100 \mathrm{mg}$ progesterone/day on Days $1-4$ or with vehicle (control) (Exp. 2)

\begin{tabular}{lcc}
\hline & \multicolumn{2}{c}{ Donor treatments* } \\
\cline { 2 - 3 } $\begin{array}{l}\text { Stage of } \\
\text { embryo development }\end{array}$ & $\begin{array}{c}\text { Control } \\
(n=8)\end{array}$ & $\begin{array}{c}\text { Progesterone } \\
(n=10)\end{array}$ \\
\hline Hatched blastocyst & 0 & 4 \\
Expanded blastocyst & 0 & 8 \\
Blastocyst & 34 & 6 \\
Early blastocyst & 14 & 13 \\
Compacted morula & 18 & 21 \\
Degenerative embryo & 27 & 8 \\
Unfertilized oocyte & 15 & 5 \\
\hline
\end{tabular}

*Number of embryos presented in each classification.

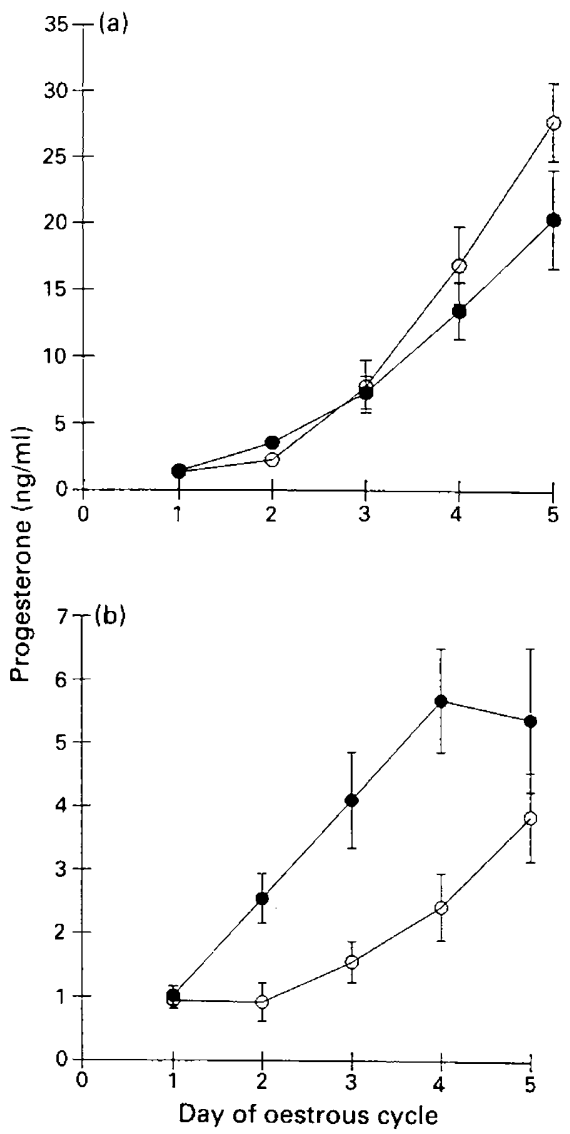

Fig. 2. Peripheral plasma progesterone concentrations in (a) superovulated donor and (b) cyclic cows; progesterone-treated $(\bigcirc)$ and vehicle $(O)$. Note the rapid increase in plasma progesterone concentration of donor females relative to vehicle- and progesterone-treated cyclic cows. 


\section{Discussion}

Results of the present study demonstrate that administration of exogenous progesterone on Days 1-4 of the recipient's oestrous cycle allows 'older' ( +3 days) embryos to become established and pregnancy to be maintained in the cow. These data are consistent with the successful maintenance of pregnancy with advanced ( +4 days) embryos transferred to recipient ewes which received progesterone shortly after oestrus (Moore, 1975; Lawson \& Cahill, 1983). Without treatment with progesterone, only 1 of 21 asynchronous recipient cows maintained pregnancy with advanced embryos. Previous studies have clearly established that pregnancy rates are reduced when embryos are $>48$ h from synchrony with the recipient's uterine environment in cattle (Rowson et al., 1972; Newcomb \& Rowson, 1975; Putney et al., 1988) and sheep (Moore \& Shelton, 1964; Rowson \& Moore, 1966). Together, these studies indicate that progesterone stimulates changes within the uterine environment which regulate receptivity and promote embryo survival.

The role of progesterone in controlling uterine secretory function is evident from the increase in protein accumulation within the uterine lumen as well as the qualitative changes in protein synthesis during the luteal phase of the oestrous cycle of pregnancy (Bartol et al., 1985; Vallet et al., 1987; Garrett et al., 1988b; Ashworth \& Bazer, 1989). Wilmut et al. (1985) have provided direct evidence that steroids influence embryonic growth and survival, although the two are not necessarily synonymous. A highly asynchronous uterine environment relative to the ovine embryo can either retard embryo development (if placed in a uterus earlier in the cycle relative to the donor) or accelerate embryo growth (when transferred to an advanced uterine environment). Although embryo growth can be stimulated by transfer to an advanced uterine environment, these embryos appear to be inadequate in their ability to secrete signals necessary for the establishment of pregnancy, since luteolysis occurs at the expected time in the cycle. Wilmut $\&$ Sales (1981) found that abnormal development of asynchronous-transferred embryos occurred during the phase of rapid conceptus growth (Days 9-12). Embryo survival may depend upon the differentiation of embryonic and trophoblastic germ layers and/or the expression of receptors for steroids, growth factors or other growth modulating compounds necessary for creation of a normal developmental response to an advanced maternal uterine environment. Changes in early embryo development after asynchronous transfer were not evaluated in our study, but the similarity of embryo development as well as the known mechanism of maintenance of pregnancy in cows and ewes suggest that a similar response may also occur in cows.

Garrett et al. (1988b) demonstrated that administration of progesterone after oestrous expression in cows altered the synthesis and release of uterine polypeptides on Days 5 and 14. Treatment of cyclic cows with a similar progesterone treatment shortens the interoestrous interval by $\sim 3$ days (Garrett et al., 1988a, present study), which is similar to reports in sheep (Ottobre et al., 1980; Lawson \& Cahill, 1983). These results support the role of progesterone in regulation of not only uterine secretion, but also maturation of the luteolytic pathway controlling prostaglandin synthesis and release. Although there was a 3-day shift in cycle length in cows, treatment of mated cows with progesterone resulted in enhanced embryo growth on Day 14 (Garrett et al., 1988b). However, in contrast to the transfer of embryos to an advanced uterus ( +3 days), embryos were normal as they synthesized bovine trophoblast protein-1(bTP-1), which is necessary for preventing luteolysis and maintaining pregnancy. The ability of 'native' embryos to establish pregnancy in a progesteroneadvanced uterine environment, in contrast to asynchronously transferred embryos ( +3 days), may result from the passage of these embryos through the early changes in uterine secretion between Days 2 and 8 stimulated by progesterone administration. Transfer of embryos into an advanced uterine environment of a recipient may not provide the programming necessary for embryos to adapt.

Although the total number of ova recovered was reduced in superovulated cows treated with progesterone, the number of transferable embryos recovered was not different. The number and variation in viable embryos recovered is comparable to that in previous studies (Elsden et al., 1976; 
Putney et al., 1988). The reduced number of total ova recovered in progesterone-treated cows could be caused by earlier loss of nonviable ova by the advanced uterine environment or by difference in ovulation rate between the 2 groups. Based on palpation, ovulation was not different as cows averaged $\sim 12$ and 10 corpora lutea in the vehicle- and progesterone-treated cows, respectively.

Effects of progesterone administration on enhancing early embryo development were not apparent in Exp. 2. Progesterone treatment of superovulated donors did not influence embryo development compared with nontreated donors on Day 7. This is as expected since a rapid increase in plasma progesterone in progesterone- and vehicle-superovulated donors indicates that a similar uterine environment would have developed; but embryo development, based on subjective morphological evaluation, was not advanced compared with embryos collected at comparable times from non-superovulated cattle (Flechon \& Renard, 1978; Betteridge, 1988; Maurer \& Chenault, 1983).

These results suggest that alterations in growth of embryos occur after hatching when progesterone-regulated endometrial protein secretion would be established to support rapid conceptus growth and attachment. Changes in blastocyst growth were only apparent after Day 10 in the asynchronous-transfer studies in sheep (Wilmut \& Sales, 1981) and at Day 14 in progesterone-treated cows (Garrett et al., 1988b). Whether changes in embryo growth during the luteal phase are controlled by the rate at which progesterone increases $(>1 \mathrm{ng} / \mathrm{ml})$ after oestrus or the length of uterine exposure to progesterone is not known. The former hypothesis is supported by the results of Nephew et al. (1990) which indicate that cycle length and embryo growth are associated with the initiation of luteal function in the ewe. The rapid increase in plasma progesterone in superovulated cows would suggest that recipients that are advanced in synchrony from the donor would provide a more appropriate uterine environment. This hypothesis is supported by the results of Putney et al. (1988), which indicated that higher pregnancy rates were achieved when recipients expressed oestrus $3648 \mathrm{~h}$ before the donor. This advantage with advanced recipients has been reported in other studies (Halley et al., 1979; Hasler et al., 1987).

Wilmut et al. (1985) have indicated that creating the appropriate hormonal profile in recipients would allow more predictable timing for co-ordinating stage of embryo development with the uterine secretory environment of the recipient. Although use of progesterone administration to improve synchrony of embryo transfer is encouraging, caution is warranted. Treatment of cows $(n=6)$ with progesterone shortly after initiation of oestrus $(24 \mathrm{~h})$ for 3 days instead of 4 results in cycle lengths of 12 days (T. C. Fox \& R. D. Geisert, unpublished results). Therefore, consideration must be given to the timing as well as length of progesterone administration to recipients. Also, although progesterone treatment increases embryo growth, maturation of the endometrialluteolytic pathway occurs earlier. Thus, the embryo is not provided with any additional time to secrete bTP-I for maintenance of pregnancy compared with the time taken in the normal oestrous cycle. If the progesterone-stimulated increase in embryo growth could be disconnected from onset of earlier luteolysis in cows, an increase in success of transfer may be achieved.

Journal Article No. 5902 of Agricultural Experiment Station, Oklahoma State University, Stillwater, USA. We thank R. Blair, L. O'Neill and S. Welty for their technical assistance and $\mathrm{S}$. Geisert for typing the manuscript. This research was supported in part by USDA Grant 87-CRCR-1-2502.

\section{References}

Ashworth, C.J. \& Bazer, F.W. (1989) Changes in ovine conceptus and endometrial function following asynchronous embryo transfer or administration of progesterone. Biol. Reprod. 40, 425-433.

Ashworth, C.J., Sales, D.I. \& Wilmut, I. (1989) Evidence of an association between the survival of embryos and the periovulatory plasma progesterone concentration in the ewe. J. Reprod. Fert. 87, 23-32.

Bartol, F.F., Roberts, R.M., Bazer, F.W. \& Thatcher, W.W. (1985) Characterization of proteins produced in vitro by bovine endometrial explants. Biol. Reprod. 33, 745-759. 
Betteridge, K.J. (1988) The anatomy and physiology of pre-attachment bovine embryos. Theriogenology 29, $155-187$.

Betteridge, K.J., Eaglesome, M.D., Randall, G.C.B. \& Mitchell, D. (1980) Collection, description and transfer of embryos from cattle 10-16 days after oestrus. J. Reprod. Fert. 59, 205216.

Elsden, R.P., Hasler, J.F. \& Seidel, G.E. (1976) Nonsurgical recovery of bovine eggs. Theriogenology 6 , $523-532$.

Flechon, J.E. \& Renard, J.P. (1978) A scanning electron microscope study of the hatching of bovine blastocysts in vitro. J. Reprod. Fert. 53, 9-12.

Garrett, J.E., Geisert, R.D., Zavy, M.T., Gries, L.K., Wettemann, R.P. \& Buchanan, D.S. (1988a) Effect of exogenous progesterone on prostaglandin $F-2 \alpha$ release and the interestrous interval in the bovine. Prostaglandins 36, 85 96.

Garrett, J.E., Geisert, R.D., Zavy, M.T. \& Morgan, G. L. (1988b) Evidence for maternal regulation of early conceptus growth and development in beef cattle. $J$. Reprod. Fert. 84, 437-446.

Halley, S.M., Rhobes, R.C., III, McKellar, L.D. \& Randel, R.D. (1979) Successful superovulation, nonsurgical collection and transfer of embryos from Brahman cows. Theriogenology 12, 97-108.

Hare, W.C.D., Singh, E.L., Betteridge, K.J., Eaglesome, M.D., Randall, G.C.B., Mitchell, D., Bilton, R.J. \& Trounson, A.O. (1980) Chromosomal analysis of 159 bovine embryos collected 12 to 18 days after estrus. Can. J. Genet. Cytol. 22, 615626.

Hasler, J.F., McCauley, A.D., Lathrop, W.F. \& Foote, R.H. (1987) Effect of donor-embryo-recipient interactions on pregnancy rate in a large-scale bovine embryo transfer program. Theriogenology 27 , $139-168$.

Lamming, G.E., Darwash, A.O. \& Beck, H.L. (1989) Corpus luteum function in dairy cows and embryo mortality. J. Reprod. Fert., Suppl. 37, 245-252.

Lawson, R.A.S. \& Cahill, L.P. (1983) Modification of the embryo maternal relationship in ewes by progesterone treatment early in the estrous cycle. $J$. Reprod. Fert. 67, 473-475.

Lawson, R.A.S., Parr, R.A. \& Cahill, L.P. (1983) Evidence for maternal control of blastocyst growth after asynchronous transfer of embryos to the uterus of the ewe. J. Reprod. Fert. 67, 477-483.

Lusby, K.S., Wettemann, R.P. \& Turman, E.J. (1981) Effects of early weaning calves from first-calf heifers on calf and heifer performance. J. Anim. Sci. 53, 1193-1197.

Markette, K.L., Seidal, G.E., Jr. \& Elsden, R.P. (1985) Estimation of embryonic losses in bovine embryo transfer recipients from progesterone profiles and returns to estrus. Theriogenology 23, 45-62.

Maurer, R.R. \& Chenault, J.R. (1983) Fertilization failure and embryonic mortality in parous and nonparous beef cattle. J. Anim. Sci. 56, 1186-1189.
Maurer, R.R. \& Echternkamp, S.E. (1982) Hormonal asynchrony and embryonic development. Theriogenology 17, 17-22.

Moore, N.W. (1975) Progesterone requirements for the maintenance of pregnancy in the ovariectomized ewe. J. Reprod. Fert. 43, 286287.

Moore, N.W. \& Shelton, J.N. (1964) Egg transfer in sheep. Effect of degree of synchronization between donor and recipient, age of egg, and site of transfer on the survival of transferred eggs. J. Reprod. Fert. 7, 145152.

Nephew, K.P., McClure, K.E. \& Pope, W.F. (1990) Disparities during early pregnancy among ewes with estrous cycie of different durations. Biol. Reprod. 42, Suppl. 1, 52.

Newcomb, R. \& Rowson, L.E.A. (1975) Conception rate after transfer of cow eggs in relation to synchronization of oestrus and age of egg. J. Reprod. Fert. 43, 539-541.

Ottobre, J.S., Lewis, G.S., Thayne, W.V. \& Inskeep, E.K. (1980) Mechanism by which progesterone shortens the estrous cycle of the ewe. Biol. Reprod. 23, 1046-1053.

Putney, D.J., Thatcher, W.W., Drost, M., Wright, J.M. \& DeLorenzo, M.A. (1988) Influence of environmental temperature on reproductive performance of bovine embryo donors and recipients in the southwest region of the United States. Theriogenology 30, 905-922.

Rowson, L.E.A., Lawson, R.A.S., Moore, R.M. \& Baker, A.A. (1972) Egg transfer in the cow: Synchronization requirements. J. Reprod. Fert. 28, 427-431.

Rowson, L.E.A. \& Moor, R.M. (1966) Embryo transfer in the sheep: The significance of synchronizing oestrus in donor and recipient animal. J. Reprod. Fert. 11, 207-212.

Spector, P.C., Goodnight, J.H., Sall, J.P. \& Sarle, W.S. (I985) The GLM procedure. In SAS User's Guide: Statistics, Version 5 edn, pp. 433-507, SAS Institute, Cary, NC.

Steel, R.D.G. \& Torrie, J.H. (1980) Homogeneity of variance. In Principles and Procedures of Statistics: A Biometrical Approach, 2nd edn, pp. 471-472, McGraw-Hill Book Co., NY.

Vallet, J.L., Bazer, F.W. \& Roberts, R.M. (1987) The effect of ovine trophoblast protein-one on endometrial protein secretion and cyclic nucleotides. Biol. Reprod. 37, 1307-1316.

Wilmut, I. \& Sales, D.I. (1981) Effect of an asynchronous environment on embryo development in sheep. $J$. Reprod. Fert. 61, 179-184.

Wilmut, I., Sales, D.I. \& Ashworth, C.J. (1985) The influence of variation in embryo stage and maternal hormone profiles on embryo survival in farm animals. Theriogenology 23, 107-119.

Wilmut, I., Sales, D.E. \& Ashworth, C.J. (1986) Maternal and embryonic factors associated with prenatal loss in mammals. J. Reprod. Fert. 76, 851-864. 